\title{
B-type natriuretic peptide and mortality in extremely low birth weight infants with pulmonary hypertension: a retrospective cohort analysis
}

Alain Cuna, Jegen Kandasamy and Brian Sims*

\begin{abstract}
Background: B-type natriuretic peptide (BNP) is a strong predictor of mortality in adult patients with various forms of pulmonary hypertension (PH) and may be a strong prognostic marker in extremely low birth weight (ELBW) infants with bronchopulmonary dysplasia (BPD) associated PH as well. We sought to assess the relationship between BNP levels and all-cause mortality in a cohort of ELBW infants with BPD and PH.

Methods: We retrospectively identified ELBW infants with BPD and PH who had serum BNP levels measured as part of routine clinical care in the neonatal intensive care unit. Peak serum BNP levels were correlated with survival to discharge or death.

Results: Thirty-six ELBW infants (mean gestational age $26.0 \pm 1.9$ weeks and mean birth weight $740 \pm 290$ grams) with BPD and PH had available survival data and had serum BNP levels measured. Peak BNP level was significantly lower among infants who survived than among those who died $(128 \mathrm{pg} / \mathrm{ml}$, [IQR 23 to 463] vs. $997 \mathrm{pg} / \mathrm{ml}$, [IQR 278 to 1770], $P<0.004$ ). On multivariate Cox proportional hazard analysis, BNP predicted survival independent of age, gender, and BPD severity. Area under receiver operator characteristic analysis identified a BNP value of $220 \mathrm{pg} / \mathrm{ml}$ to have $90 \%$ sensitivity and $65 \%$ specificity in predicting mortality.
\end{abstract}

Conclusion: BNP estimation may be useful as a prognostic marker of all-cause mortality in ELBW infants with BPD associated $\mathrm{PH}$.

Keywords: Prematurity, Bronchopulmonary dysplasia, Prognostic factors, Outcome

\section{Background}

Pulmonary hypertension $(\mathrm{PH})$ is increasingly recognized as an important complication of prematurity and bronchopulmonary dysplasia (BPD) [1,2]. Retrospective studies have estimated that 25 to $37 \%$ of infants with BPD develop PH $[3,4]$, and a recent prospective study showed that 1 out of 6 extremely low birth weight (ELBW) infants develop PH [5]. This is concerning as $\mathrm{PH}$ in the BPD population is associated with worse outcomes, with mortality rates ranging between $14 \%$ and $38 \%$ in retrospective studies [3,4,6-8] and $12 \%$ in one prospective study [5]. Currently there are no clear guidelines for assessment and monitoring

\footnotetext{
* Correspondence: bsims@peds.uab.edu

Department of Pediatrics, Division of Neonatology, University of Alabama at Birmingham, 619 S 19th St, Birmingham 35249, AL, USA
}

of ELBW infants with PH [9]. Identification of a widely available biomarker with strong prognostic information is highly desirable for risk stratification and management.

B-type natriuretic peptide (BNP), a cardiac biomarker released by myocytes in response to ventricular stretch [10], is an established marker of ventricular dysfunction [11]. In adult patients with $\mathrm{PH}$, levels of BNP correlate with hemodynamic parameters of disease severity and has been shown to be predictive of survival [12-16]. It is possible that BNP could also prove useful in assessing severity and prognosis of ELBW infants with BPD and PH. The purpose of this present study is to evaluate the utility of BNP as a potential marker for predicting mortality among ELBW infants with BPD and PH. 


\section{Methods}

This retrospective cohort study was conducted in the Neonatal Intensive Care Units at the University of Alabama at Birmingham Hospital and Children's of Alabama Hospital between August 2010 and December 2012. This study was approved by the University of Alabama at Birmingham Institutional Review Board, with waiver of informed consent.

\section{Study population}

We identified from the neonatology database all ELBW infants with BPD in whom serum BNP concentrations were measured as part of routine clinical assessment for PH. Diagnosis of BPD was based on the National Institute of Health consensus definition [17]. Diagnosis of PH was based on the presence of at least 1 of the following echocardiographic findings: (1) presence of elevated tricuspid regurgitation jet, (2) flattening of intraventricular septum, (3) right ventricular hypertrophy, or (4) right to left shunting. Echocardiogram studies were performed by certified technicians using Sonos 5500 ultrasound machine (Philips Healthcare) and were independently interpreted and reported by pediatric cardiologists. Infants with structural heart disease other than a patent ductus arteriosus (PDA) or patent foramen ovale and those with multiple congenital anomalies were excluded.

\section{Data collection}

Data were collected from the infants' medical records. Data extracted included baseline demographic information, respiratory support at 36 weeks postmenstrual age, diagnosis and severity of BPD, other co-morbidities of prematurity including PDA, severe intraventricular hemorrhage, proven necrotizing enterocolitis, medications used for treatment of $\mathrm{PH}$, and serum BNP levels. Peak BNP level was defined as the highest BNP concentration measured during the course of the hospitalization. The primary study outcome was all cause mortality.

\section{BNP for screening and follow-up of $\mathrm{PH}$}

The use of BNP as an adjunct to echocardiography for screening and follow-up of BPD-associated PH has been adopted by our group since August 2010. ELBW infants who remained on oxygen and/or respiratory support at 28 days of age were evaluated with echocardiography and serum BNP measurement shortly thereafter (before 6 weeks of age) to screen for $\mathrm{PH}$. Infants diagnosed with $\mathrm{PH}$ based on echocardiographic findings were then evaluated with monthly echocardiography and BNP testing for follow-up of severity of $\mathrm{PH}$. Infants who did not show signs of $\mathrm{PH}$ on initial screening may be subsequently re-evaluated by echocardiography and BNP measurement based on clinical suspicion of $\mathrm{PH}$. BNP levels were measured in $\mathrm{pg} / \mathrm{mL}$ using the ADVIA Centaur ${ }^{\oplus}$ BNP Assay (Siemens USA).
Our general management strategy for PH in BPD infants utilizes a stepwise approach. Initial treatment included optimizing respiratory support to provide adequate oxygenation and prevent periods of hypoxemia. If oxygenation remains labile, pulmonary vasodilator therapy is added sequentially starting with inhaled nitric oxide, then sildenafil, and, for severe cases of $\mathrm{PH}$, bosentan is sometimes considered.

\section{Statistical analyses}

Values are presented as counts and percentages, mean \pm standard deviation, or median and interquartile range (IQR, 25th and 75th percentile). Skewed data (BNP levels) were transformed logarithmically to produce a normal distribution for appropriate parametric testing. Comparison of baseline subject characteristics in survivors vs. non-survivors was performed with independent samples t-test, Mann-Whitney U, or Fisher's exact test, as appropriate. Possible correlations between demographic and clinical variables and outcome were investigated using uni-and multivariate Cox proportional hazard analysis and hazard ratios with two-sided 95\% confidence interval (CI) are provided. Before performing survival analysis, a receiver operating characteristic curve was created to determine the peak BNP level that provided the best combination of sensitivity and specificity for predicting the composite endpoint. Survival analysis was performed with KaplanMeier and Cox proportional hazards modeling. The logrank test was used to determine statistical significance between Kaplan-Meier survival curves. BNP level, age, sex, and BPD severity were all included in the hazard model. All statistical tests were 2 -sided, and $P$ value of $<0.05$ was deemed significant.

\section{Results}

\section{Baseline characteristics}

During the study period, 36 preterm infants with BPDassociated PH had BNP values available. The mean gestational age was $26.0 \pm 1.9$ weeks and the mean birth weight was $740 \pm 290$ grams. The differences in characteristics between survivors and non-survivors are shown in Table 1. No differences were seen between survivors and nonsurvivors in terms of gestational age, birth weight, sex, or race. There were also no differences in terms of being small for gestational age (SGA), respiratory support at 36 weeks postmenstrual age and severity of BPD, severe intraventricular hemorrhage, or proven necrotizing enterocolitis. Of note, 6 of the 17 survivors (35\%) were noted to have a PDA at the time of echocardiographic diagnosis of $\mathrm{PH}$ compared to none of the non-survivors $(\mathrm{P}=0.006)$.

\section{Relation of peak BNP and mortality from all causes}

The median peak BNP level was significantly lower among infants who survived than among those who died (128 pg/ml, [IQR 23 to 463] vs. $997 \mathrm{pg} / \mathrm{ml}$, [IQR 278 to 
Table 1 Baseline and clinical characteristics for all patients, survivors and non-survivors

\begin{tabular}{|c|c|c|c|c|}
\hline & $\begin{array}{c}\text { All patients } \\
n=36\end{array}$ & $\begin{array}{c}\text { Survivors } \\
n=17\end{array}$ & $\begin{array}{c}\text { Non-survivors } \\
n=19\end{array}$ & $P$ value \\
\hline \multicolumn{5}{|l|}{ Demographics } \\
\hline Birth weight, grams & $740 \pm 290$ & $745 \pm 293$ & $736 \pm 295$ & 0.92 \\
\hline Gender, Male & $19(53)$ & $9(53)$ & $10(53)$ & 1.0 \\
\hline Race & & & & 0.86 \\
\hline Caucasian & $15(42)$ & $7(41)$ & $8(42)$ & \\
\hline African American & $20(55)$ & $9(53)$ & $11(58)$ & \\
\hline Hispanic & $1(3)$ & $1(6)$ & $0(0)$ & \\
\hline Gestational age, weeks & $26.0 \pm 1.9$ & $26.2 \pm 2.4$ & $25.8 \pm 1.4$ & 0.59 \\
\hline Small for gestational age & $13(36)$ & $6(35)$ & $7(37)$ & 1.0 \\
\hline Respiratory support at 36 weeks postmenstrual age & & & & 0.62 \\
\hline Mechanical ventilation & $15(42)$ & $8(47)$ & $7(37)$ & \\
\hline CPAP & $5(14)$ & $1(6)$ & $4(21)$ & \\
\hline $\mathrm{O}_{2}$ supplementation & $13(36)$ & $7(41)$ & $6(32)$ & \\
\hline Room air & $3(8)$ & $1(6)$ & $2(10)$ & \\
\hline \multicolumn{5}{|l|}{ Morbidity } \\
\hline $\mathrm{BPD}$ & & & & 0.61 \\
\hline Mild & $3(8)$ & $1(6)$ & $2(10.5)$ & \\
\hline Moderate & $2(6)$ & $0(0)$ & $2(10.5)$ & \\
\hline Severe & $31(86)$ & $16(94)$ & $15(79)$ & \\
\hline Patent ductus arteriosus & $6(16)$ & $6(35)$ & $0(0)$ & 0.006 \\
\hline Severe intraventricular hemorrhage (grade 3 or 4) & $9(25)$ & $6(35)$ & $3(8)$ & 0.26 \\
\hline Proven necrotizing enterocolitis (stage 2 or 3 ) & $5(14)$ & $4(24)$ & $1(5)$ & 0.17 \\
\hline Peak BNP, pg/mL & $351(82,1461)$ & $128(23,463)$ & $997(278,1770)$ & 0.004 \\
\hline \multicolumn{5}{|l|}{ Medications } \\
\hline Inhaled nitric oxide & $32(89)$ & $13(76)$ & $19(100)$ & 0.04 \\
\hline Sildenafil & $31(86)$ & $12(71)$ & $19(100)$ & 0.02 \\
\hline Bosentan & $18(50)$ & $7(41)$ & $11(58)$ & 0.51 \\
\hline
\end{tabular}

Data shown as $n$ (\%), mean \pm standard deviation, or median (interquartile range). $P$ values refer to independent samples t-test, Mann-Whitney $U$, or Fisher's exact test.

$B N P$ B-type natriuretic peptide, $B P D$ bronchopulmonary dysplasia, CPAP continuous positive airway pressure, $\mathrm{O}_{2}$ oxygen.

1770], $\mathrm{P}<0.004$ ) (Figure 1). Analysis using a receiver operating characteristic curve shown in Figure 2 identified a peak BNP cutoff value of $220 \mathrm{pg} / \mathrm{ml}$ to have the best combination of sensitivity $(90 \%)$ and specificity (65\%) for predicting mortality from all causes.

Comparison of baseline characteristics between subjects with peak $\mathrm{BNP}<220 \mathrm{pg} / \mathrm{ml}$ and those with $\geq 220 \mathrm{pg} / \mathrm{ml}$ showed no significant differences. Kaplan-Meier survival analysis shown in Figure 3 demonstrated significantly lower survival for subjects with peak BNP level of $\geq 220 \mathrm{pg} / \mathrm{ml}$ After controlling for age, sex, and BPD severity, multivariate Cox proportional hazards modeling showed that a BNP level of $\geq 220 \mathrm{pg} / \mathrm{ml}$ independently increased the likelihood of death (hazard ratio 5.1, 95\% CI 1.1 to $22.4, \mathrm{P}=0.03$ ).

\section{Discussion}

Our study demonstrates that peak BNP level obtained during the course of hospitalization in a cohort of preterm infants with BPD-associated $\mathrm{PH}$ provides prognostic information on all-cause mortality. This is consistent with previous studies suggesting that elevated BNP is associated with increased mortality in adult patients with various forms of PH $[12,14,16]$. Our group has also previously demonstrated that BNP levels may be useful in screening for $\mathrm{PH}$ in preterm infants with BPD [18]. The findings of this current study extend the clinical usefulness of BNP as a prognostic biomarker in preterm infants with BPD-associated PH.

Preterm infants with BPD-associated $\mathrm{PH}$ are difficult to manage. Availability of a non-invasive and readily available prognostic biomarker is beneficial for risk stratification 


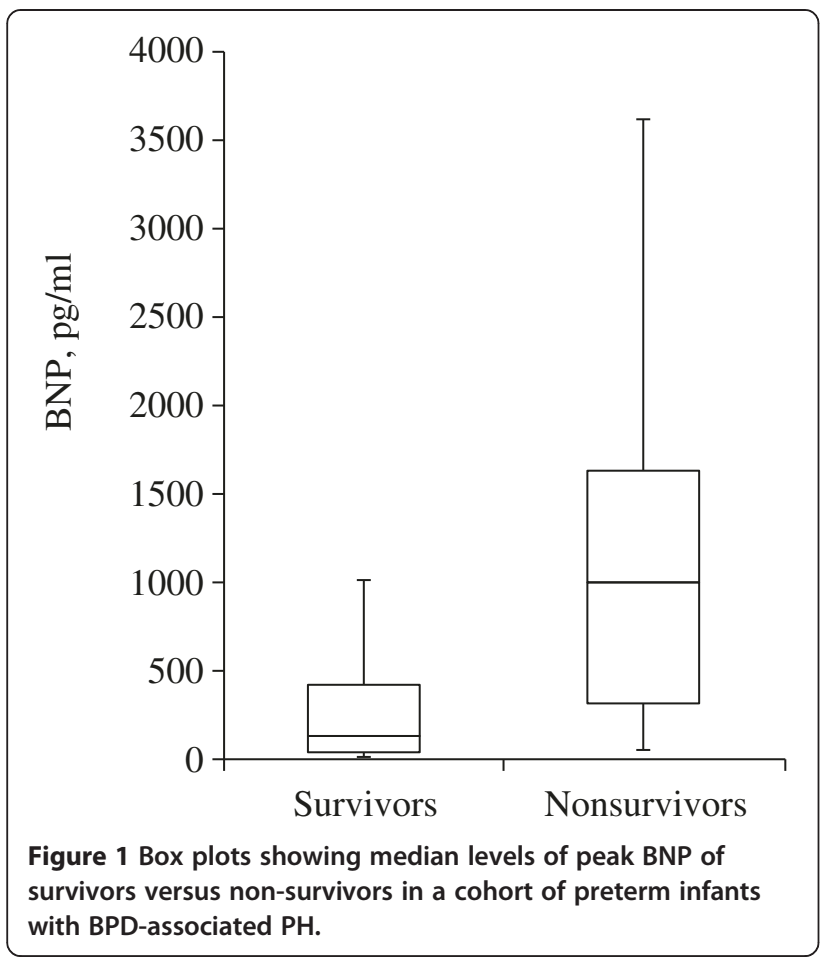

and optimal management [19]. Identification of which infants are at increased risk and which are at low risk for adverse outcomes allows appropriate allocation of resources to infants who would benefit the most from specific treatment strategies, as well as prevent overtreatment of infants at low risk. Currently, echocardiography is used to

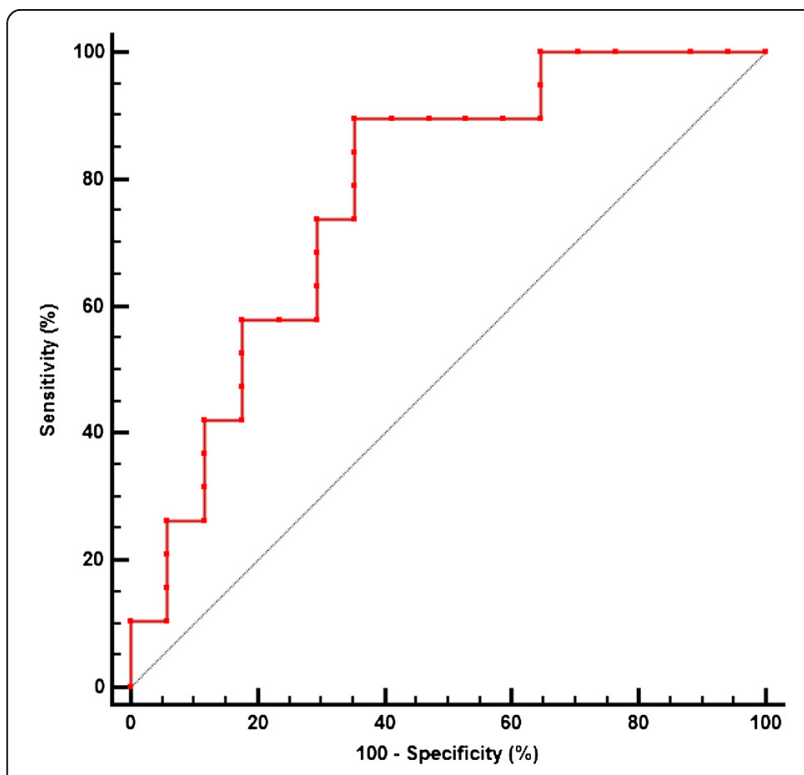

Figure 2 Receiver operating characteristic curve demonstrating that a BNP level of $220 \mathrm{pg} / \mathrm{ml}$ results in a sensitivity of $90 \%$ and a specificity of $65 \%$ for predicting mortality in preterm infants with BPD-associated PH.

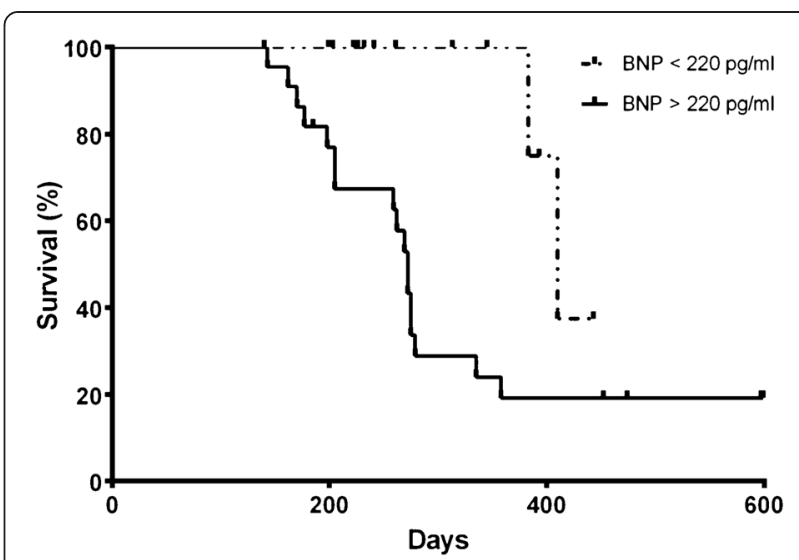

Figure 3 Kaplan-Meier cumulative survival curves showing cumulative rates of survival for 36 preterm infants with BPD-associated PH stratified by the identified BNP cut-off value. Infants with $B N P \geq 220 \mathrm{pg} / \mathrm{ml}$ differed significantly from infants with $B N P<220 \mathrm{pg} / \mathrm{ml}$.

determine severity of $\mathrm{PH}$ and assess risk for adverse outcomes. Though noninvasive and available in most centers, echocardiography is resource intensive and has limited sensitivity in determining severity of $\mathrm{PH}[20]$.

Our study suggests that elevated BNP levels may be useful for risk stratification in this vulnerable patient population. Our analysis was limited due to the small sample size and the fact that BNP measurements were not obtained at similar time points. Nevertheless, we did observe trends showing that BNP levels decreasing over time were seen among infants that survived; and that BNP levels increasing or remaining elevated over time were seen among infants who died. This observation needs further validation in a larger prospective study with well-defined BNP estimation time points, but it does suggest that serial BNP measurement may be helpful in identifying infants at high and low risk for mortality; and that treatment, including the intensity of surveillance and the use of aggressive pharmacologic and interventional therapy, may be adjusted accordingly.

More than one-third of infants with BPD-associated $\mathrm{PH}$ in our study were SGA. This is consistent with previous studies which reported that SGA infants are at an increased risk for developing $\mathrm{PH}[5,21]$. It is interesting to note however that no difference in SGA status between survivors and non-survivors was seen in our study. This may indicate that despite the higher risk for developing PH, SGA infants are not necessarily at any greater risk for mortality compared to appropriate for gestational age infants with $\mathrm{PH}$. Larger prospective studies will need to be carried out to validate this hypothesis.

It is also interesting to note that the presence of a PDA at the time of initial echocardiographic diagnosis of $\mathrm{PH}$ was noted in 6 of the 17 survivors versus none in those who died. We postulate that the presence of a PDA 
may be protective, allowing a "pop-off valve" that alleviates elevated pulmonary pressures [22,23]. Another difference is that more non-survivors were noted to be on inhaled nitric oxide or sildenafil than survivors. This most likely represents more severe disease among non-survivors requiring more intensive treatment for $\mathrm{PH}$ rather than any perceived harm from inhaled nitric oxide or sildenafil.

Four infants with peak BNP levels below the identified threshold of $220 \mathrm{pg} / \mathrm{ml}$ had late mortality, as reflected by a drop in their Kaplan-Meier survival curve at around 400 days of life. (Figure 3) Review of medical records indicate that the cause of death in 2 of these infants were due to disease processes not directly related to $\mathrm{PH}$ (sepsis, withdrawal of support for severe encephalopathy), which may explain why BNP levels remained below the threshold in these non-survivors. The remaining 2 infants however were identified to have died because of severe BPD and PH. This finding suggests that in a small subset of preterm infants, BNP levels may not rise as expected despite the presence of severe $\mathrm{PH}$. Further studies are needed to validate this observation as well as identify characteristics that may determine which infants with $\mathrm{PH}$ fail to exhibit a rise in serum BNP.

The strengths of our study include its well defined cohort of preterm infants with BPD-associated $\mathrm{PH}$ and highly relevant primary outcome of mortality versus survival. Our study is limited by its small sample population, its retrospective nature, and the possibility that infants included are biased towards those with more severe disease. An important limitation is the lack of follow-up data on survivors, including rehospitalization and post-discharge mortality. Another limitation is our lack of data on renal function, as renal dysfunction is known to contribute to higher BNP levels $[24,25]$. A prospective study involving a larger sample size is needed to validate the usefulness of BNP as a prognostic marker in this population. Further studies are also needed to show whether treatment strategies guided by BNP levels will lead to decreased morbidity and mortality.

\section{Conclusion}

Our findings suggest that elevated BNP levels in hospitalized preterm infants with $\mathrm{BPD}$-associated $\mathrm{PH}$ may be used to identify infants at risk for death. BNP levels may be included in the risk stratification of preterm infants with $\mathrm{PH}$, and higher BNP levels may warrant increased surveillance and management.

\footnotetext{
Abbreviations

BNP: B-type natriuretic peptide; BPD: Bronchopulmonary dysplasia; $\mathrm{Cl}$ : Confidence interval; ELBW: Extremely low birth weight; IQR: Interquartile range; $\mathrm{PH}$ : Pulmonary hypertension; PDA: Patent ductus arteriosus; SGA: Small for gestational age.
}

\section{Competing interests}

The authors declare that they have no competing interests.

\section{Authors' contributions}

AC contributed to the design of the study, was responsible for the management and retrieval of data from the neonatal database, contributed to initial data analysis and interpretation, drafted the initial manuscript, and approved the final manuscript as submitted. JK was responsible for the management and retrieval of data from the neonatal database, contributed to initial data analysis and interpretation, and approved the final manuscript as submitted. BS conceptualized and designed the study, supervised all aspects of the study, critically reviewed and revised the manuscript, and approved the final manuscript as submitted. All authors read and approved the final manuscript.

\section{Acknowledgements}

The authors would like to acknowledge the Division of Neonatology at University of Alabama at Birmingham for their support and guidance in the performance of this study. No external funding was secured for this study, and the authors have no financial relationships relevant to this article to disclose.

Received: 10 December 2013 Accepted: 4 March 2014

Published: 11 March 2014

\section{References}

1. Hislop AA, Haworth SG: Pulmonary vascular damage and the development of cor pulmonale following hyaline membrane disease. Pediatr Pulmonol 1990, 9(3):152-161.

2. Goodman G, Perkin RM, Anas NG, Sperling DR, Hicks DA, Rowen M: Pulmonary hypertension in infants with bronchopulmonary dysplasia. J Pediatr 1988, 112(1):67-72.

3. An HS, Bae EJ, Kim GB, Kwon BS, Beak JS, Kim EK, Kim HS, Choi JH, Noh Cl, Yun YS: Pulmonary hypertension in preterm infants with bronchopulmonary dysplasia. Korean Circ J 2010, 40(3):131-136.

4. Slaughter JL, Pakrashi T, Jones DE, South AP, Shah TA: Echocardiographic detection of pulmonary hypertension in extremely low birth weight infants with bronchopulmonary dysplasia requiring prolonged positive pressure ventilation. J Perinatol 2011, 31(10):635-640.

5. Bhat $\mathrm{R}$, Salas AA, Foster C, Carlo WA, Ambalavanan N: Prospective analysis of pulmonary hypertension in extremely low birth weight infants. Pediatrics 2012, 129(3):e682-e689.

6. Kumar VH, Hutchison AA, Lakshminrusimha S, Morin FC, Wynn RJ, Ryan RM: Characteristics of pulmonary hypertension in preterm neonates. J Perinatol 2007, 27(4):214-219.

7. Kim GB: Pulmonary hypertension in infants with bronchopulmonary dysplasia. Korean J Pediatr 2010, 53(6):688-693.

8. Khemani E, McElhinney DB, Rhein L, Andrade O, Lacro RV, Thomas KC, Mullen MP: Pulmonary artery hypertension in formerly premature infants with bronchopulmonary dysplasia: clinical features and outcomes in the surfactant era. Pediatrics 2007, 120(6):1260-1269.

9. Collaro JM, Romer LH, Stuart BD, Coulson JD, Everett AD, Lawson EE, Brenner Jl, Brown AT, Nies MK, Sekar P, Nogee LM, McGrath-Morrow SA: Frontiers in pulmonary hypertension in infants and children with bronchopulmonary dysplasia. Pediatr Pulmonol 2012, 47(11):1042-1053.

10. Levin ER, Gardner DG, Samson WK: Natriuretic peptides. N Engl J Med 1998, 339(5):321-328.

11. de Lemos JA, McGuire DK, Drazner MH: B-type natriuretic peptide in cardiovascular disease. Lancet 2003, 362(9380):316-322.

12. Andreassen AK, Wergeland R, Simonsen S, Geiran O, Guevara C, Ueland T: $\mathrm{N}$-terminal pro-B-type natriuretic peptide as an indicator of disease severity in a heterogeneous group of patients with chronic precapillary pulmonary hypertension. Am J Cardiol 2006, 98(4):525-529.

13. Nagaya N, Nishikimi T, Okano Y, Uematsu M, Satoh T, Kyotani S, Kuribayashi S, Hamada S, Kakishita M, Nakanishi N, Takamiya M, Kunieda T, Matsuo H, Kangawa K: Plasma brain natriuretic peptide levels increase in proportion to the extent of right ventricular dysfunction in pulmonary hypertension. J Am Coll Cardiol 1998, 31(1):202-208.

14. Nagaya N, Nishikimi T, Uematsu M, Satoh T, Kyotani S, Sakamaki F, Kakishita M, Fukushima K, Okano Y, Nakanishi N, Miyatake K, Kangawa K: Plasma brain natriuretic peptide as a prognostic indicator in patients with primary pulmonary hypertension. Circulation 2000, 102(8):865-870.

15. Goto K, Arai M, Watanabe A, Hasegawa A, Nakano A, Kurabayashi M: Utility of echocardiography versus BNP level for the prediction of pulmonary 
arterial pressure in patients with pulmonary arterial hypertension. Int Heart J 2010, 51(5):343-347.

16. Mauritz GJ, Rizopoulos D, Groepenhoff H, Tiede H, Felix J, Eilers P, Bosboom J, Postmus PE, Westerhof N, Vonk-Noordegraaf A: Usefulness of serial N-terminal pro-B-type natriuretic peptide measurements for determining prognosis in patients with pulmonary arterial hypertension. Am J Cardiol 2011, 108(11):1645-1650.

17. Jobe AH, Bancalari E: Bronchopulmonary dysplasia. Am J Respir Crit Care Med 2001, 163(7):1723-1729.

18. Cuna A, Kandasamy J, Fineberg N, Sims B: B-type natriuretic peptide is a biomarker for pulmonary hypertension in preterm infants with bronchopulmonary dysplasia. Res Rep Neonatology 2013, 2013(3):33-36.

19. Kragelund C, Grønning B, Køber L, Hildebrandt P, Steffensen R: N-terminal pro-B-type natriuretic peptide and long-term mortality in stable coronary heart disease. N Engl J Med 2005, 352(7):666-675.

20. Mourani PM, Sontag MK, Younoszai A, Ivy DD, Abman SH: Clinical utility of echocardiography for the diagnosis and management of pulmonary vascular disease in young children with chronic lung disease. Pediatrics 2008, 121(2):317-325.

21. Check J, Gotteiner N, Liu X, Su E, Porta N, Steinhorn R, Mestan KK: Fetal growth restriction and pulmonary hypertension in premature infants with bronchopulmonary dysplasia. J Perinatol 2013, 33(7):553-557.

22. Hines MH: Invited commentary. Ann Thorac Surg 2006, 81(1):234-235.

23. Rosenzweig EB, Feinstein JA, Humpl T, Ivy DD: Pulmonary arterial hypertension in children: diagnostic work-up and challenges. Prog Pediatr Cardiol 2009, 27(1):4-11.

24. DeFilippi CR, Seliger SL, Maynard S, Christenson RH: Impact of renal disease on natriuretic peptide testing for diagnosing decompensated heart failure and predicting mortality. Clin Chem 2007, 53(8):1511-1519.

25. McCullough PA, Duc P, Omland T, McCord J, Nowak RM, Hollander JE, Herrmann HC, Steg PG, Westheim A, Knudsen CW, Storrow AB, Abraham WT, Lamba S, Wu AH, Perez A, Clopton P, Krishnaswamy P, Kazanegra R, Maisel AS, Breathing Not Properly Multinational Study Investigators: B-type natriuretic peptide and renal function in the diagnosis of heart failure: an analysis from the breathing Not properly multinational study. Am J Kidney Dis 2003, 41(3):571-579.

\section{Submit your next manuscript to BioMed Central and take full advantage of:}

- Convenient online submission

- Thorough peer review

- No space constraints or color figure charges

- Immediate publication on acceptance

- Inclusion in PubMed, CAS, Scopus and Google Scholar

- Research which is freely available for redistribution 